\title{
Effect of Exercise on Fasting Blood Glucose and Oral Glucose Tolerance Tests In Offspring of Type 2 Diabetic and Non-Diabetic Parents.
}

\author{
*Dr Emmanuel.O.Taiwo. \\ *Corresponding author: *Dr Emmanuel.O.Taiwo.
}

\begin{abstract}
:
Objectives: It is uncertain if exercise could influence the occurrence of T2DM in offspring of diabetic parents. Therefore this study was designed to assess the effect of exercise on fasting blood glucose and oral Glucose Tolerance Test on offspring of T2DM parents compared with offspring of non-diabetic parents.

Design: This study involved selection of 10 offspring of T2DM parents attending University College Hospital, Ibadan and 10 offspring of non-diabetic parents who are undergraduate students of the University of Ibadan, Nigeria. Participants were randomly assigned into four groups: 5 Normal-weight Offspring of Non-Diabetic Parents (NONDP), 5 Normal-weight Offspring of Diabetic Parents (NODP), 5 Overweight Offspring of NonDiabetic Parents (OONDP) and 5 Overweight Offspring of Diabetic Parents (OODP). Each participant followed a protocol of graded exercise using the tummy trimmer everyday spending 30-45 minutes daily for 24 weeks. Blood samples were obtained after an overnight fasting for determination of fasting blood glucose using standard methods at baseline, six week, 12 week, 18 week and 24 week, respectively. Data were analyzed using descriptive statistic and repeated ANOVA with significant at $P<0.05$.

Results: At baseline, Oral GTT were also carried out before the beginning of exercise and repeated at the end of 24 weeks of exercise. There were reductions though not significant in fasting blood glucose $(\mathrm{mg} / \mathrm{dL})$ viz in NONDP: $91.00 \pm 3.71$ to $84.50 \pm 3.34$, NODP: $100.67 \pm 3.75$ to $88.17 \pm 0.75$, OONDP:93.67 \pm 5.82 to $87.17 \pm 4.98$ and OODP $90.83 \pm 5.25$ to82.83 2.37 at 24 weeks.

Conclusions: Graded exercise reduced fasting blood glucose in all the groups. The clinical importance of graded exercise in prevention of diabetes mellitus among offspring of diabetic parents is a useful intervention.

Keywords: Graded exercise, Diabetic parents' offspring, Fasting Blood Glucose.

Word count: 254
\end{abstract}

\section{Introduction}

Diabetes mellitus, commonly known as diabetes, is a disorder of intermediary carbohydrate, protein and lipid metabolism resulting from relative or absolute insulin deficiency. It is characterized by hyperglycemia, glucosuria, polydipsia, polyuria, polyphagia and weight loss. It is usually associated with secondary alterations in glucose, fat and protein metabolism, leading to many biochemical disorders. It is characterized by peripheral insulin resistance, impaired regulation of hepatic glucose production with declining $\beta$-cell function and eventually leading to $\beta$-cell failure ${ }^{1}$

While 19 million people world-wide have type 2 diabetes mellitus, 54 million individuals show impaired fasting glucose as adults which may represent a pre-diabetic state ${ }^{2}$.This carbohydrate-insulin imbalance becomes one of the most common cause of death in the United States ${ }^{3}$. The America diabetes association(ADA) has lowered the diagnostic cut off point for impaired fasting Glucose from $110 \mathrm{mg} / \mathrm{dl}$ to $100 \mathrm{mg} / \mathrm{dl}$ (approximately $6.1-5.5 \mathrm{mmol} /$ litre) to improve prediction of type 2 diabetes ${ }^{4}$.

A family history of type 2 diabetes mellitus (T2DM) predisposes individuals to developing clinical diabetes ${ }^{5}$ with first degree relative of patients with T2DM. having a 30-70\% increased risk of developing the disease $^{6}$. Heritability of diabetes is suggested to be associated with overweight/obesity ${ }^{7}$

The goal of the present study was to explore the effect of exercise on fasting blood sugar and Oral Glucose Tolerance Test (OGTT) in normoglycaemic offspring of T2DM patients

\section{Methods}

Experimental interventional study was carried out in which blood sample was collected from offspring of patients with type 2 diabetes mellitus and normoglycemic offspring of non- diabetic parents. The parents of the test group were attending the medical out-patient clinic (MOP) of the University College Hospital (UCH), Ibadan and Catholic Hospital Oluyoro, Oke-Ofa, Ibadan, South Western, Nigeria.The normoglycemic offspring of non-diabetic parents aged 25years and above were randomly selected from general population of Ibadan 
Community, Ibadan, and South-Western, Nigeria as well as undergraduate students of University of Ibadan. These are normoglycemic offspring of non-diabetic with normal weight that served as control subjects.

The participants were divided into four groups, $\mathrm{n}=5$ as follows:

A - Overweight /Obese offspring of DM parents (OODP).

B - Normal weight/ Normal Body Mass Index (BMI) offspring of DM parents (NODP).

$\mathrm{C}$ - Overweight / Obese offspring of non-diabetic parents (OONDP).

D -Normal BMI / weight offspring of non-diabetic parents (NONDP)

The study was approved by the University of Ibadan Teaching Hospital Ethical Committee (UI /UCH joint IRB) and Catholic Hospital Ethical Committee prior to its implementation

For determination of Oral Glucose Tolerance Test (OGTT), blood was taken by needle prick and fasting blood glucose was measured by Accucheck glucometer at Ominute, 30 minutes, 60 minutes, 90 minutes and 120 minutes consecutively after administration of $75 \mathrm{~g}$ of oral glucose for determination of Oral Glucose Tolerance Test (OGTT). This is repeated as follows: Baseline measurement and after 6, 12, 18 and 24 weeks.

Body mass index (BMI) reading values for the subject were read off as displayed on the screen of Omron equipment. The BMI values were used to group subjects into four categories. Underweight BMI $<18.5 \mathrm{~kg} / \mathrm{m}^{2}$ Normal weight - BMI $=18.5$ to $24.9 \mathrm{~kg} / \mathrm{m}^{2}$ Overweight BMI $=25-29.9 \mathrm{~kg} / \mathrm{m}^{2}$ Obese $-\mathrm{BMI}=$ $>30.0 \mathrm{~kg} \cdot \mathrm{m}^{2} 8$.

Omron fat estimator was used to measure the BMI based on the weight and height of the subject. The subject stood uprightly bare-footed put on light clothing. The subject held his stretched hands forward as if he was riding a motor-bike.

BMI was read off as displayed on the screen of the Omron fat estimator (reliability and reproducibility index \pm $0.01 \%)$. The readings were recorded in the recording book.

Tummy trimmer, a portable, aerobic exercise, lightweight equipment (European Home Choice Company, Lagos, Nigeria) was selected for the study. It is in-door isotonic equipment. It is compact and can fit right in the subject's brief case.

During each phase of exercise the Tummy trimmer, a portable lightweight equipment, is held at the two handles and the sole of the two feet are put inside the pedal rest while the subject assumes different positions. The subject then pulls the tummy trimmer's spring towards himself or herself either while lying flat or sitting up on the floor or carpeted hard surface.

Subject sits up with legs straight, leans his or her body backwards until completely lying back with head on floor. He/she returns to sitting position in harmonic fashion. The subject was advised to start slowly and work up to repetitions as she/he feels comfortable with harmoniously.

The subject was advised to lie flat on floor, extend his/her legs straight up in the air. He will be keeping his/her back on the floor and raise the lower legs without bending them. The subject was advised to sit erect with legs straight longitudinally, he/she raises the handle to tummy height using arms only.

Finally, subject was advised to lie flat on the floor while he/she bends the knees up to his/her chest. He/She makes a circular motion push feet up and then round towards the floor again. The different positions were observed for exercise period of 30 to 40 minutes (a video clip of the exercise procedure was shown to the subject before the commencement of the exercise).

Each subject was advised as follows:

(1) $\mathrm{He} / \mathrm{She}$ to undergo the 4 phases of exercise between 30 and 40 minutes daily (either in the mornings or evenings).

(2) $\mathrm{He} / \mathrm{She}$ to contact the researcher on cell phone anytime when he/she has any problems with the unit.

(3) There were regular cell phone calls made to each of the subjects by the research assistant to ensure compliance with exercise schedule.

(4) The research assistant called them on cell phone and sent s.m.s (Short Message Service) to them to keep return appointments every six weeks. This was done one or two days before appointment schedule.

Statistical analysis was carried out by using the ANOVA.The data obtained was analyzed using computer statistical programme package SPSS version 15.0. Probability value of $\mathbf{P}$ less than 0.05 was considered statistically significant.

\section{Results}

This shows Oral Glucose Tolerance test (OGTT) results in the four groups as indicated.

In Tables 1to 2 and Figures 1 and 2, in all the groups, there were variations in the patterns of the levels of glucose from 0 minutes to 120 minutes.

In over- weight/obese offspring of diabetic parents (OODP) the level reduced from $.90 .83 \pm 5.25$ at 0 time to $86.33 \pm 3.02 \mathrm{mg} / \mathrm{dl}$ at 120 minutes. 
In normal weight offspring of diabetic parents (NODP) the level of glucose reduced from $100.67 \pm 3.75$ to $95.00 \pm 1.61 \mathrm{mg} / \mathrm{dl}$ after 120 minutes.

In overweight/obese offspring of non- diabetic parents (OONDP) blood glucose level was reduced from $93.67 \pm 5.82$ basal level to $87.83+2.87 \mathrm{mg} / \mathrm{dl}$ after 120 minutes.

In NONDP the level of glucose reduced from $91.00 \pm 3.71$ to $83.33 \pm 4.28 \mathrm{mg} / \mathrm{dl}$ at 120 minutes (Table 1).

Figure 1 is combined glucose level graphs at onset of study which shows the glucose tolerance over all the groups. In the NODP, the blood glucose level started from $91.33 \pm 1.52 \mathrm{mg} / \mathrm{dl}$ and peaked at 30 minutes with $150.00 .00 \pm 9.66 * \mathrm{mg} / \mathrm{dl}$ and reduced finally to $88.17 \pm 0.75 \mathrm{mg} / \mathrm{dl}$. This shows a variation of patterns of the glucose tolerance curve.

Table 2 shows Glucose Tolerance test (GTT) results in the four groups after six months of exercise.

In all the groups, the Glucose levels followed the normal rise and fall of glucose tolerance curve.

In OODP, the Glucose level rose from $89.83 \pm 3.82 \mathrm{mg} / \mathrm{dl}$ at 0 minute to $132.17 \pm 8.86$ at 30 minutes and fell to $117.33 \pm 8.79$ at 60 minutes finally dropped to $82.83 \pm 2.37 \mathrm{mg} / \mathrm{dl}$ at 120 minutes.

In NONDP, the Glucose level rose from $87.17 \pm 2.3 \mathrm{mg} / \mathrm{dl}$ at 0 minutes to $106.83 \pm 8.17$ at 30 minutes, and fell to $86.00 \pm 3.21$ at 90 minutes and finally fell to $84.50 \pm 3.34 \mathrm{mg} / \mathrm{dl}$ at 120 minutes

Figure 2 is a combined glucose tolerance level graphs after six months of exercise. The exercise has improved the pattern of glucose tolerance curves. The level of glucose in NODP reduced to $106.00+6 . .87 \mathrm{mg} / \mathrm{dl}$ at 90 minutes of exercise. Peak blood glucose level also occurred at 30minutes compared with 60minutes before exercise.

Table 1: OGTT results in the four groups before exercise (All values are in $\mathrm{mg} / \mathrm{dl}$ ).

\begin{tabular}{|l|l|l|l|l|l|}
\hline & $\mathbf{0 ~ m i n s}$ & $\mathbf{3 0}$ mins & $\mathbf{6 0 ~ m i n s}$ & $\mathbf{9 0 ~ m i n s}$ & $\mathbf{1 2 0}$ mins \\
\hline $\begin{array}{l}\text { Overweight/Obese Offspring } \\
\text { of Diabetic Parents (OODP) }\end{array}$ & $90.83 \pm 5.25$ & $121.33 \pm 8.06$ & $111.33 \pm 6.08$ & $93.67 \pm 5.18$ & $86.33 \pm 3.02$ \\
\hline $\begin{array}{l}\text { Normal Weight Offspring of } \\
\text { Diabetic Parents (NODP) }\end{array}$ & $100.67 \pm 3.75$ & $126.67 \pm 8.43$ & $136.67 \pm 14.76$ & $121.33 \pm 9.64 *$ & $95.00 \pm 1.61$ \\
\hline $\begin{array}{l}\text { Overweight/Obese Offspring } \\
\text { of Non-Diabetic Parents } \\
\text { (OONDP) }\end{array}$ & $93.67 \pm 5.82$ & $113.83 \pm 11.07$ & $113.00 \pm 9.63$ & $94.00 \pm 5.29$ & $87.83 \pm 2.87$ \\
\hline $\begin{array}{l}\text { Normal Weight Offspring of } \\
\text { Non-Diabetic Parents } \\
\text { (NONDP) }\end{array}$ & $91.00 \pm 3.71$ & $109.00 \pm 6.01$ & $118.30 \pm 5.16$ & $86.00 \pm 6.61$ & $83.33 \pm 4.28$ \\
\hline p & 0.435 & 0.491 & 0.259 & $0.006^{*}$ & 0.084 \\
\hline
\end{tabular}

All values are mean \pm SEM, $n=5$

p- comparison of Glucose levels across groups

$\mathrm{P}=$ ANOVA $\mathrm{p}$ - value.

At Onset

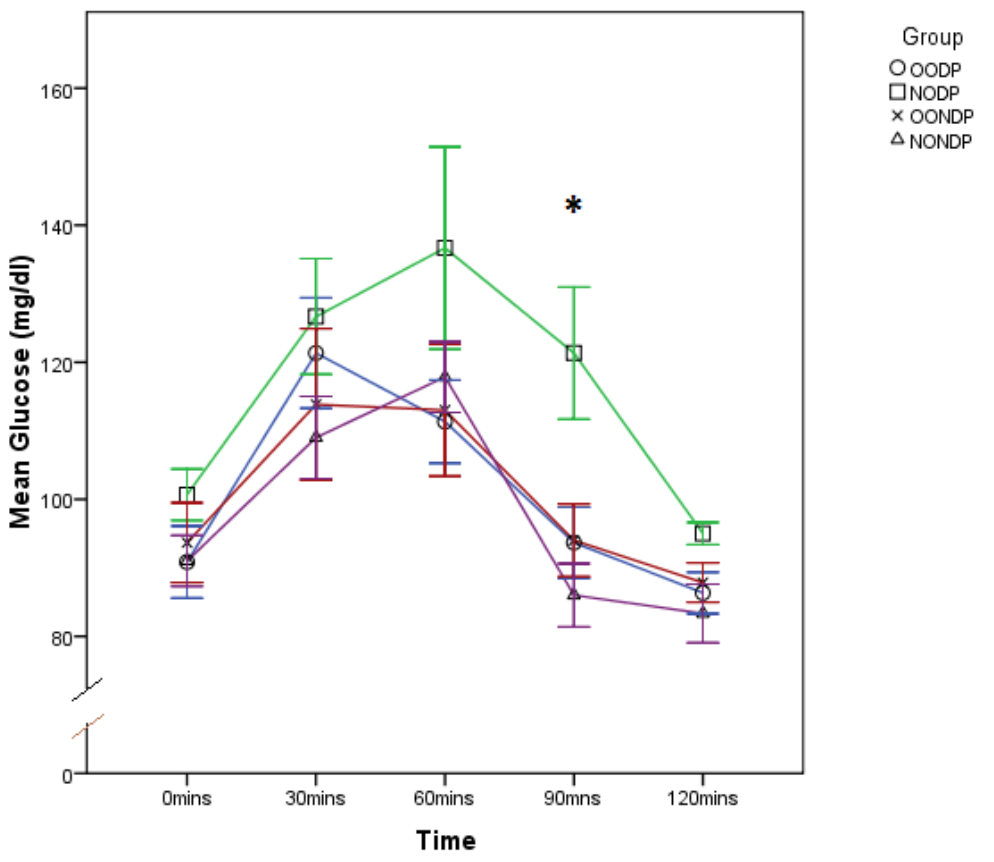

*Significant at $\mathrm{p}<0.05$

Figure 1: Oral Glucose Tolerance Test in all the groups (at onset) 
Table 2: OGTT results in the four groups after 6 months exercise (All values are in $\mathrm{mg} / \mathrm{dl}$ ).

\begin{tabular}{|l|l|l|l|l|l|}
\hline & $\mathbf{0 ~ m i n s}$ & $\mathbf{3 0}$ mins & $\mathbf{6 0}$ mins & $\mathbf{9 0 ~ m i n s}$ & $\mathbf{1 2 0}$ mins \\
\hline $\begin{array}{l}\text { Overweight/Obese offspring } \\
\text { of diabetic parents (OODP) }\end{array}$ & $89.83 \pm 3.82$ & $132.17 \pm 8.86$ & $117.33 \pm 8.79$ & $86.50 \pm 3.01$ & $82.83 \pm 2.37$ \\
\hline $\begin{array}{l}\text { Normal weight offspring of } \\
\text { diabetic parents (NODP) }\end{array}$ & $91.33 \pm 1.52$ & $150.00 \pm 9.66^{*}$ & $137.00 \pm 12.40$ & $106.00 \pm 6.87$ & $88.17 \pm 0.75$ \\
\hline $\begin{array}{l}\text { Overweight/Obese offspring } \\
\text { of Non-diabetic parents } \\
\text { (OONDP) }\end{array}$ & $88.50 \pm 4.73$ & $116.50 \pm 11.27$ & $109.17 \pm 9.07$ & $90.00 \pm 4.88$ & $87.17 \pm 4.98$ \\
\hline $\begin{array}{l}\text { Normal weight offspring of } \\
\text { Non-diabetic parents } \\
\text { (NONDP) }\end{array}$ & $87.17 \pm 2.73$ & $106.83 \pm 8.17$ & $112.33 \pm 3.58$ & $86.00 \pm 3.21$ & $84.50 \pm 3.34$ \\
\hline $\mathrm{p}$ & 0.844 & $0.024^{*}$ & 0.160 & 0.116 & 0.644 \\
\hline
\end{tabular}

All values are mean \pm SEM, $n=5$

p- comparison of Glucose levels across groups

$\mathrm{P}=\mathrm{p}$ value in ANOVA scale.

After 6 months

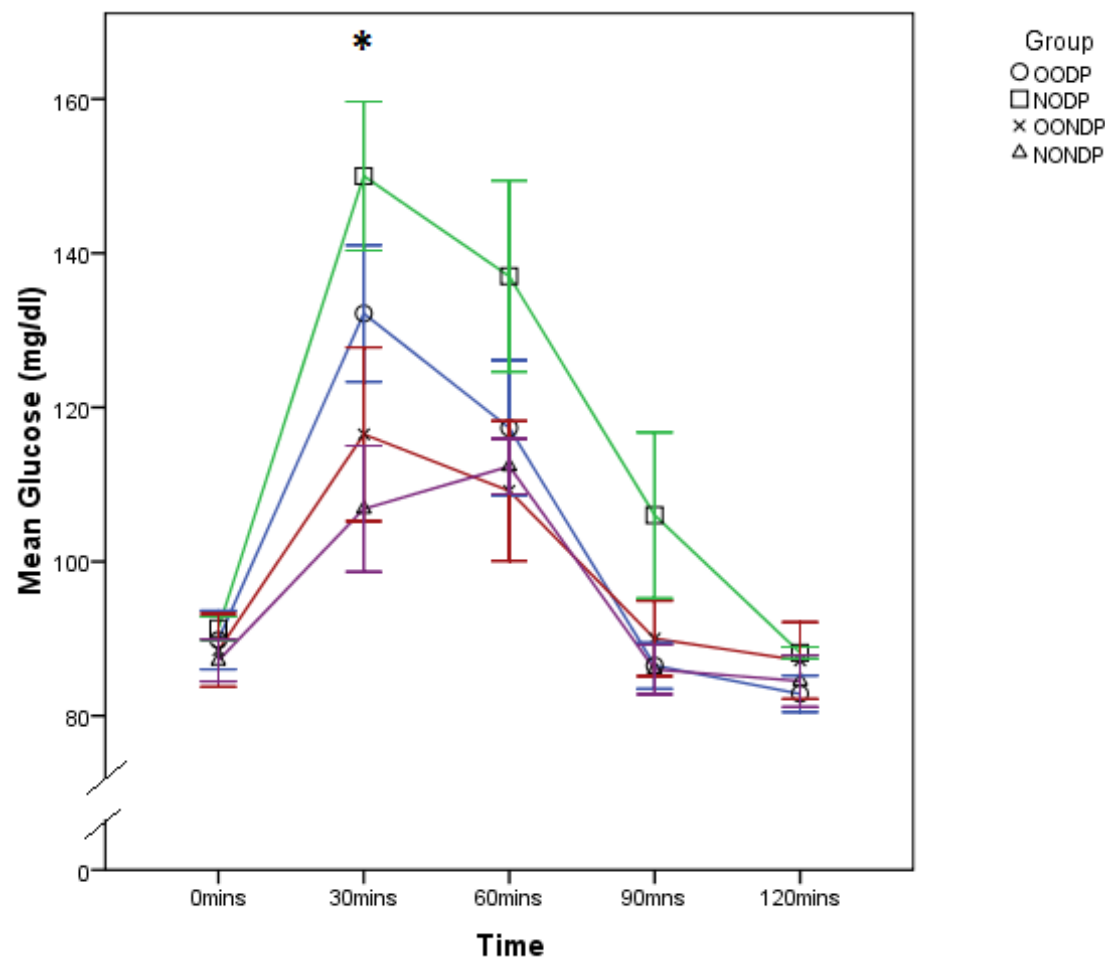

Significant at $\mathrm{p}<0.05$

Figure 2: Oral Glucose Tolerance Test in all the groups (after 6 months)

\section{Discussion}

In this present study Glucose tolerance curve indicate that the glucose tolerance curve in normal weight offspring of diabetic parents NODP did not follow the normal curve patterns as shown in figure 1 and 2 . However, after subjecting the group to exercise the normal glucose tolerance curve pattern was achieved. Therefore, the level at 0 minute was returned to over two hours of glucose ingestion. This indicated that six months of exercise has improved the insulin sensitivity especially at 30mintes of NODP

Physical exercise can be an important adjunct in the management of both non-insulin dependent DM and insulin-dependent DM. Over the past years, considerable progress has been made in understanding the molecular basis for these clinically important effects of physical exercise.

Similar to the effect of insulin, a single bout of exercise has been reported to increase the rate of glucose uptake into the contracting skeletal muscles, a process that is regulated by the translocation of GLUT4 glucose transporters to the plasma membrane and transverse tubules of the skeletal muscle cells ${ }^{9}$. Exercise and insulin utilize different signaling pathways, both of which lead to the activation of glucose transport, which explains why people with insulin resistance can increase muscle glucose transport in response to an acute bout of exercise ${ }^{10}$. 
Exercise training in humans results in numerous beneficial adaptations in skeletal muscles, which include an elevation in GLUT4 expression ${ }^{10}$. The elevation in muscle GLUT4 in trained individuals contribute to an increase in the responsiveness of muscle glucose uptake to insulin, although not all studies show that exercise training in patients with diabetes mellitus improves overall glucose control ${ }^{10}$.Thus, there is now extensive epidemiological evidence demonstrating that long-term regular physical exercise can significantly reduce the risk of developing non-insulin dependent diabetes ${ }^{10}$.

At any point in time, the glycemic response to exogeneous glucose is the balance between the rate at which glucose appears in the systemic circulation and the rate at which the gastric contents are passed on to the small intestine.

Henninger et a $1(2015)^{11}$ revealed that markers of adipose tissue cell hypertrophy and dysfunction showed altered trends prior to the development of impaired glucose tolerance or T2DM in individual with a first-degree family history of diabetes. Excess as well as suppressed secretion of adipokines are typical manifestations of adiposities dysfunction ${ }^{12}$.

The present study revealed cnclusively a significant decrease in fasting blood level after six months of exercise. The change in the patterns of glucose tolerance curve after 24 weeks of exercise show that reduction in weight cum improved insulin sensitivity is an important finding in offspring of diabetic parents. Recent studies have indicated that fasting bloo glucose ( FBG) level is a strong and consistent predictor of diabetic risk $^{13}{ }^{14}$. The FBG level has been proven to have high reproducibility, small variability and a favorable application to clinical Practice ${ }^{15}$.

In conclusion, the present study shows that subjecting offspring of T2DM to exercise will reduce the FBG level as well as improve their glucose tolerance. More studies should be carried out to ascertain this by using larger population and at different locations.

\section{References}

[1]. Bacha F., Lee S.,Gungor N., Arslanian S. (2010) From pre-diabetes to type 2 diabetes in obese youth: pathophysiological characteristics along the spectrum of glucose dysregulation. Diabetes Care 33: 2225-2231.

[2]. Diabetes Care 20008 Aug 31 (8) 1473-8, America Diabetes Association (ADA)

[3]. Hoyert DL, Heron MP,Murphy SL, Kung H. National Vital Statistics Reports: Deaths: Final Data for 2003. Vol 54. No. 13. Hyattsville, MD: National Center for Health Statistics; 2006.

[4]. Genuth S, Alberti KG, Bennett P, et al; Expert Committee on the Diagnosis and glucose in adults in the US population: National Health And Nutrition Examination

[5]. Wagner R, Thorand B, Osterhoff MA, Müller G, Böhm A, Meisinger C et al. Family history of diabetes is associated with higher risk for prediabetes: a multicentre analysis from the German Center for Diabetes Research. Diabetologia 2013; 56: 2176-2180

[6]. Cederberg H, Stančáková A, Kuusisto J, Laakso M, Smith U. Family history of type 2 diabetes increases the risk of both obesity and its complications: is type 2 diabetes a disease of inappropriate lipid storage? J Intern Med 2015; 277: 540-551.

[7]. Goldfine AB, Beckman JA, Betensky RA, Devlin H, Hurley S, Varo N et al. Family history of diabetes is a major determinant of endothelial function. J Am Coll Cardiol 2006; 47: 2456-2461.

[8]. Kushner RF and Blatner DJ. Risk assessment of the overweight and obese patient. J Am Diet Assoc. 2005 , 105 (5 Suppl 1): S53-62.

[9]. Joram D .mul, Kristin I Stanform. Michael F. Hirshman and Laurie J. Goodyear. Prog Mol Biol Transl Sci 2015 , '35',17-37.

[10]. Andrew J Murray. Genome Med VI (12); 2009 PMC 2808733

[11]. Henninger J, Hammarstedt A, Rawshani A, Eliasson B. Metabolic predictors of impaired glucose tolerance and type 2 diabetes in a predisposed population - a prospective cohort study. BMC Endocr Disord 2015; 15: 51

[12]. Gustafson B, Gogg S, Hedjazifar S, Jenndahl L, Hammarstedt A, Smith U. Inflammation and impaired adipogenesis in hypertrophic obesity in man. Am J Physiol Endocrinol Metab 2009; 297: E999-E1003.

[13]. Tirosh A, Shai I, Tekes-Manova D, et al; Israeli Diabetes Research Group. Normal a disease of inappropriate lipid storage? J Intern Med 2015; 277: 540-551.

[14]. Nichols GAHillier TABrown JB Normal fasting plasma glucose an risk of type2 diabetes diagnosis. Am J Med 2008;121 (6) 519524

[15]. DECODE Study group; the Europpean Diabetes Epidemilogy Group, Glucose tolerance and cardiovascular mortality: comparison of fasting and 2-hour diagnostic criteria. Arch Intern Med 2001; 161 (3) 397-405.

\section{Dr Emmanuel.O. Taiwo. "Effect of Exercise on Fasting Blood Glucose and Oral Glucose Tolerance Tests In Offspring of Type 2 Diabetic and Non-Diabetic Parents." IOSR Journal of Dental and Medical Sciences (IOSR-JDMS) 16.7 (2017): 22-26.}

